\title{
Macroscopic interpretation of nano-scale scattering data in clay
}

\author{
G. BIRMPILIS*, R. AHMADI-NAGHADEH* and J. DIJKSTRA*
}

\begin{abstract}
The potential of X-ray scattering measurements for monitoring changes on the nano-scale in finegrained materials in their natural wet state is demonstrated with a series of feasibility tests on wellcontrolled kaolin samples - that is, water content, $\mathrm{pH}$ and loading history. The results indicate that subtle changes on the nanometric scale, especially the particle orientations, can be measured with high fidelity using a standard laboratory small- and wide-angle X-ray scattering instrument. This opens up possibilities for future in situ loading tests with simultaneous monitoring of the evolving changes of the fabric in fine-grained soils.
\end{abstract}

KEYWORDS: clays; fabric/structure of soils

Published with permission by the ICE under the CC-BY 4.0 license. (http://creativecommons.org/licenses/by/4.0/)

\section{NOTATION}

$d$ characteristic spacing of scatterers $(\AA)$

e void ratio

$G_{\mathrm{s}} \quad$ specific density

q $\quad$ scattering vector $\left(\AA^{-1}\right)$

$w_{1}$ liquid limit $(\%)$

$w_{\mathrm{p}}$ plastic limit $(\%)$

$2 \theta$ scattering angle $\left({ }^{\circ}\right)$

$\lambda$ wavelength of radiation $(\AA)$

$\sigma_{\mathrm{v}}^{\prime} \quad$ vertical effective stress $(\mathrm{kPa})$

\section{INTRODUCTION}

The particle size in natural soils may span many orders of magnitude and the particles are of different physico-chemical origin. In contrast to the other fractions, the emerging material response at the continuum scale of the clay fraction $(<2 \mu \mathrm{m})$ is not solely frictional (Santamarina, 2003). The large- aspect ratio and crystal structure of the clay platelets give rise to surface charges. A mixture of these nano-sized particles forms colloid structures. The intra-particle structure is that of a crystal, a product of weathering, while the interparticle structure is controlled by the dielectric environment of the pore fluid forming a poly-disperse system of agglomerated clay platelets (e.g. Mitchell \& Soga, 2005).

Most experimental techniques for studying the nanoscopic and microscopic scales in fine-grained soils are based on, among others, scanning electron microscopy (SEM), mercury intrusion porosimetry (MIP) and X-ray diffraction (XRD). The characterisation of clay crystal structures using X-rays dates back to Grim (1953). Brindley \& Kurtossy (1962); Quigley \& Thompson (1966) and Martin \& Ladd (1975) utilised XRD for the quantitative study of fabric and orientation of kaolinite minerals and sensitive clays. Iñigo et al. (2000) used an X-ray diffractometer to study the orientation of clay pastes in different water contents. XRD has been complemented with MIP and SEM to study fabric at inter-particle length scales (Diamond, 1970; Gillot, 1970;

Manuscript received 11 December 2018; first decision 10 July 2019; accepted 11 July 2019.

Published online at www.geotechniqueletters.com on 4 November 2019.

*Division of Geology and Geotechnics, Department of Architecture and Civil Engineering, Chalmers University of Technology, Gothenburg, Sweden

(Orcid:0000-0003-3792-0727).
Pusch, 1970; Bohor \& Hughes, 1971). Delage \& Lefebvre (1984) and Delage (2010) used these techniques to study sensitive clays over a wide range of evolving pore diameters. In addition, Hattab \& Fleureau (2010) and Hattab et al. (2013) processed the SEM data to extract fabric orientations. MIP has been used to record the changes of clay structure due to compaction (Tarantino \& De Col, 2008), as well as in different chemical environments (Pedrotti \& Tarantino, 2017).

Most of the above techniques are invasive and hence incompatible with the continuous monitoring of processes in a sample. Additionally, the preparation techniques influence the resulting structure (Gillot, 1970). Microscopy usually requires intense dehydration (e.g. air drying, critical point drying, freeze-drying or carbowax impregnation) to exploit the high resolutions of SEM. Environmental scanning electron microscopy is better suited for saturated samples, although Houghton \& Donald (2008) showed that difficulties with contrast remain. Contemporary state-of-the-art cryo-preparation techniques demonstrate that the preparation method not only affects the volumetric strain, but also the type of resulting fabric (cardhouse/honeycomb) (Deirieh, 2016; Deirieh et al., 2018).

Non-invasive techniques are required to extend the observation capabilities to the nano- and micro-structures of clays. $\mathrm{X}$-ray scattering is a family of non-invasive techniques, which can provide this valuable information from the nanometre to the micrometre scale. Small-angle X-ray scattering (SAXS) has already been used for the study of particle orientation in polymers (Pujari et al., 2011), the study of clay suspensions (Hanley et al., 1994; Morvan et al., 1994; Pignon et al., 1997; Zhang et al., 2003; Jung et al., 2011), pastes (Ben Rhaïem et al., 1987) and shale rocks (Lee et al., 2014; Leu et al., 2016). Smaller features of the mineralogy and sub-particle behaviour of clays can be accessed by wide-angle X-ray scattering (WAXS) measurements. XRD and WAXS are most suited to capture changes at the basal level - for example, particularly for swelling soils these have proved to be advantageous (Villar et al., 2012).

In this paper, the capabilities of X-ray scattering in the resolution of the structural characteristics of clay in its unaltered wet state are investigated. As opposed to previous SAXS studies on clay-water systems, we additionally study samples with a fabric resulting from a predefined stress history. This is achieved by combining best practices in geotechnical sample preparation with advanced material characterisation using SAXS/WAXS. Two different testing 
programmes on specimens with different preparation methods were performed to investigate the effect of the density (void ratio) and the pore fluid chemistry on the resulting nanometric structure.

\section{THEORY}

\section{$X$-ray scattering principles}

SAXS and WAXS are methods based on coherent scattering of X-rays due to heterogeneities in the electron density of the matter. Figure 1 represents the principles of the measurement method, which can be described by Bragg's law

$$
n \lambda=2 d \sin \theta
$$

where $\lambda$ is the wavelength $(\mathrm{m})$ of the radiation source and $d$ is the characteristic length of scatterers (structural units) in the material. In the case of scattering instead of the angle of diffraction $2 \theta$, the scattering vector $\boldsymbol{q}$ is used to extract information

$$
\begin{aligned}
& \boldsymbol{q}=\frac{4 \pi}{\lambda} \sin \theta \\
& \boldsymbol{q}=\frac{2 \pi}{d}
\end{aligned}
$$

In principle, scattering measurements are able to capture inter- and intra-particle distances in systems of clay particles. The measured signal corresponds to a volume-averaged response of all scatterers. In most cases the spot size is on the order of $0.2 \times 0.2 \mathrm{~mm}^{2}$, while the sample thickness ranges between 1 and $2 \mathrm{~mm}$. Insight into the anisotropy of the structure is gained by using a two-dimensional (2D) detector, which captures the scattering vector as a function of the azimuth. The size and resolution of the $2 \mathrm{D}$ detector and the sample-detector distance dictate the scattering angle, hence the range of $\boldsymbol{q}$-values that can be measured (see Fig. 1). Large $\boldsymbol{q}$-values in the WAXS configuration correspond to the crystal spacing of the clay minerals and small $\boldsymbol{q}$-values in the SAXS configurations provide measurements for the poresize distribution.

\section{SAXS/WAXS interpretation}

In the $q$-intensity plot a change of the peak width, or a shift of the peak altogether, indicates a change in the material that can be associated with mechanical strain. Orientation data are obtained from the $2 \mathrm{D}$ azimuth data - that is, plotting a single $\boldsymbol{q}$-value as a function of the azimuth. The latter will highlight preferred orientations of the structural elements, and in time-resolved tests, the change in orientation. The measurement of pore-level strain is hampered by the minimal $\boldsymbol{q}$-values (largest $d$ ) that can be captured with a

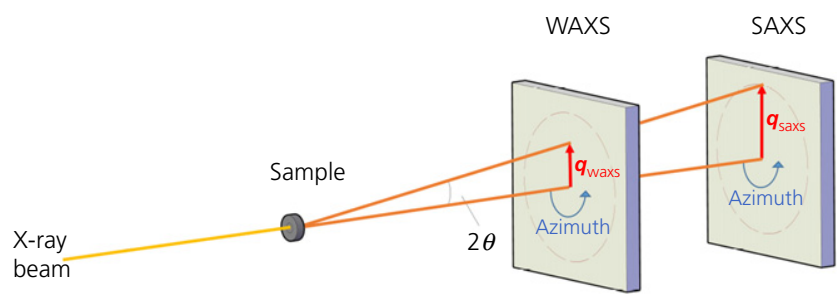

Fig. 1. Schematic representation of the WAXS and SAXS configurations. When the detector is positioned at a large distance from the sample, there are sufficient number of pixels on the detector to capture small-angle scattered photons that correspond to small $\boldsymbol{q}$-values and large characteristic lengths $d$ in the sample typical SAXS instrument, which for the instrument used is $250 \mathrm{~nm}$.

Finally, pre-set configurations and interaction regimes have been identified for the interpretation of scattering data - for example, Guinier, Porod and Kratky plots (Glatter \& Kratky, 1982). These interpretation techniques, however, are less suitable for materials with a large concentration of polydisperse and multi-component mixtures that are highly disordered (Glatter \& Kratky, 1982), such as most consolidated geo-materials.

\section{EXPERIMENTAL METHODOLOGY Instrument}

The experiments were performed at the Chalmers Material Analysis Laboratory with a SAXSLAB Mat:Nordic instrument. This instrument covers a $\boldsymbol{q}$-range from 0.0025 up to $2 \cdot 8 \AA^{-1}$, for combined SAXS/WAXS measurements, which translates into a $d$-value range of 2.24-2512 $\AA$. The dual SAXS-WAXS configuration is shown in Fig. 1. The hutch is under vacuum during the measurements, to reduce attenuation in the signal resulting from the X-ray scattering of air molecules.

\section{Materials}

Pure $(>96 \%$ w/w) kaolinite powder (Acros Organics 211740025, CAS number: 1332-58-7), with particle sizes of $1 \cdot 0-1.8 \mu \mathrm{m}$ is investigated. The specific gravity is $G_{\mathrm{s}}=2.61$ and the plastic $w_{\mathrm{p}}$ and liquid limits $w_{1}$ are 24.5 and $52.5 \%$, respectively. This leads to a plasticity index of $28 \%$, which classifies as a $\mathrm{CH}$ (high plasticity) clay.

\section{Sample preparation}

The kaolinite was probed for a total of seven different states. At this stage of investigation, due to the limited in situ testing capabilities of the SAXS instrument, the preparation of a series of independent samples is required. In the first series, the effect of pore fluid chemistry ( $\mathrm{pH}=4,7$ and 9) on the agglomeration was probed for kaolinite suspensions. The three different $\mathrm{pH}$ environments were selected to examine the resulting structure of the clay fabric in suspension, as well as after consolidation. Values of $\mathrm{pH}$ below the isoelectric

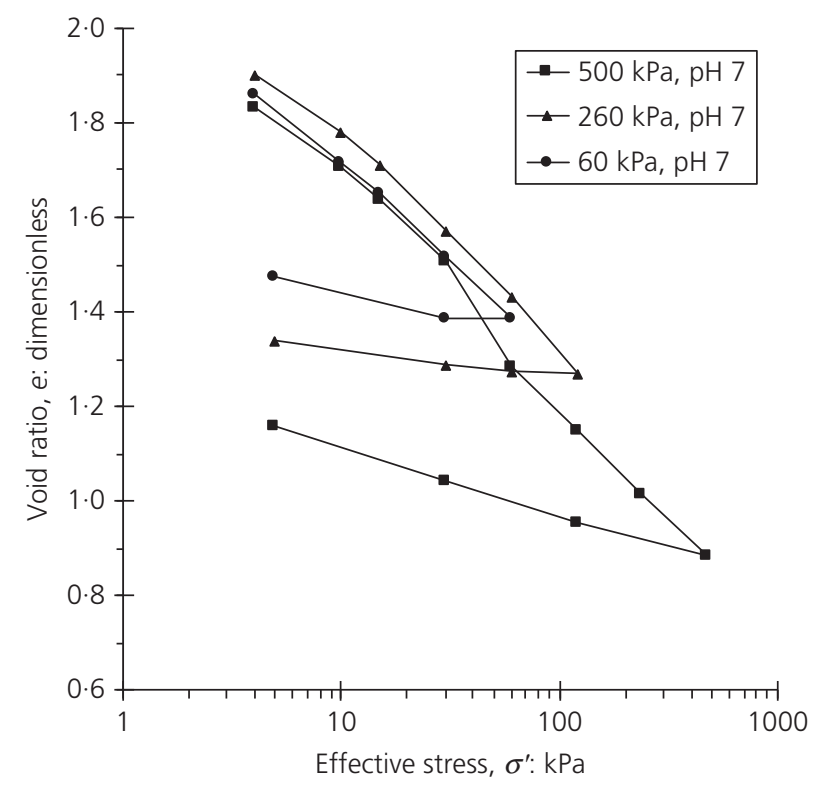

Fig. 2. 1D consolidation curve of kaolin slurry at $\mathrm{pH} 7$ 


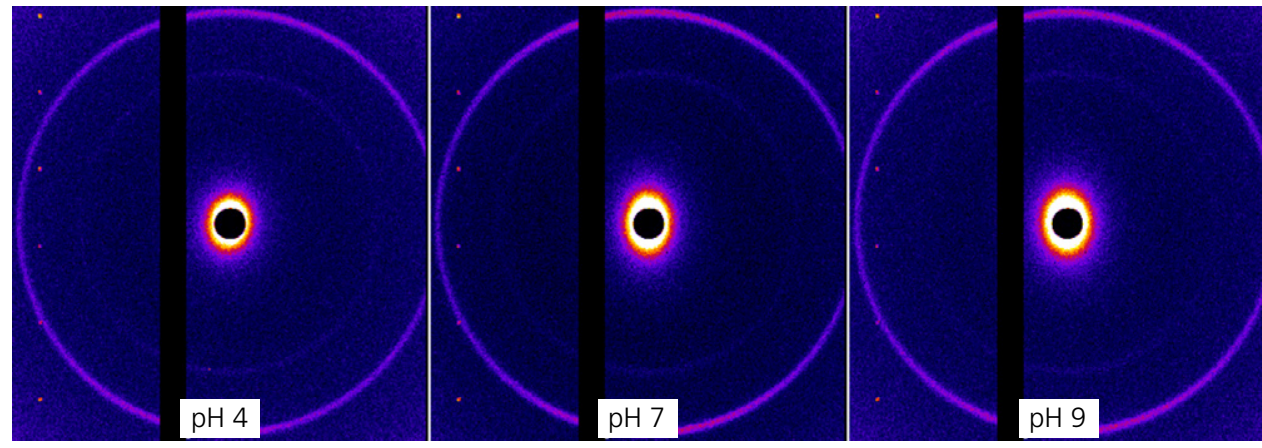

Fig. 3. 2D scattering observations for kaolin suspensions at three different $\mathrm{pH}$ levels: 4,7 and 9

point (IEP) or the point of zero charge favour the edge-to-face (EF) flocculated structure. In addition, higher $\mathrm{pH}$ values result in a dispersed and deflocculated structure (Van Olphen, 1977; Wang \& Siu, 2006).

The acidic solution was prepared by adding hydrochloric acid to distilled water, whereas for the alkaline solution, potassium hydroxide was added.

In the second series, the effect of the density of particles was studied at $\mathrm{pH}=7$. In this series, the density was gradually increased starting from a slurry $\left(1 \cdot 5 w_{1}\right)$, and subsequently consolidated to three different target stress levels. One part of the slurry was sampled directly for subsequent $\mathrm{X}$-ray scattering measurements. The slurry was consolidated after resting for $24 \mathrm{~h}$, under one-dimensional (1D) incremental loading oedometric conditions with two-sided drainage at constant temperature $\left(7^{\circ} \mathrm{C}\right)$. Three different stress levels were prepared - that is, $\sigma_{\mathrm{v}}^{\prime}=60,260$ and $500 \mathrm{kPa}$ of which the compressibility $\left(e-\log \sigma_{\mathrm{v}}^{\prime}\right)$ curve is plotted in Fig. 2.

Optically transparent and X-ray translucent borosilicate thin-walled capillaries were used to contain the suspensions, slurry and consolidated samples (wall thickness $0.16 \mathrm{~mm}$ and a cross-section of $1.4 \mathrm{~mm} \times 6.5 \mathrm{~mm}$ ) during the scattering experiments. The suspensions were sedimented according to the chemical environment of the solution before injection into the capillaries. The slurry was sampled in the tube by gentle suction. For the consolidated samples, smaller sub-samples were sampled by penetrating the thinwalled capillaries at a constant penetration rate $(0.01 \mathrm{~mm} / \mathrm{s})$ into the consolidated sample (Birmpilis et al. 2017). In all cases after sampling, the capillaries were sealed at both ends with silicon glue to prevent evaporation and to sustain the sample under vacuum conditions. To prevent the dehydration of the clay from silicon glue, an intermediate layer was applied between the clay surface and the silicon glue. The intermediate layer consisted of chemically inert mouldable paste (Sugru mouldable glue from FormFormForm Ltd.).

\section{RESULTS}

The scattering patterns of an empty capillary are subtracted from the readings, as well as the intensity levels are normalised with a zero reading of the intensities. A 2D intensity map presents the scattering pattern as observed on the detector. The dark lines are specific to the detector, while the dark spot at the centre of the beam refers to the beam stop, which blocks the X-rays that passes right through. The data are cropped to include the kaolinite mineral at $\boldsymbol{q}=0.9 \AA^{-1}$ and another mineral (most likely illite). The information on high intensity near the centre of this $2 \mathrm{D}$ image (at small $\boldsymbol{q}$-values) refers to the largest length scale, and the most reliable indicator of the number of scatterers

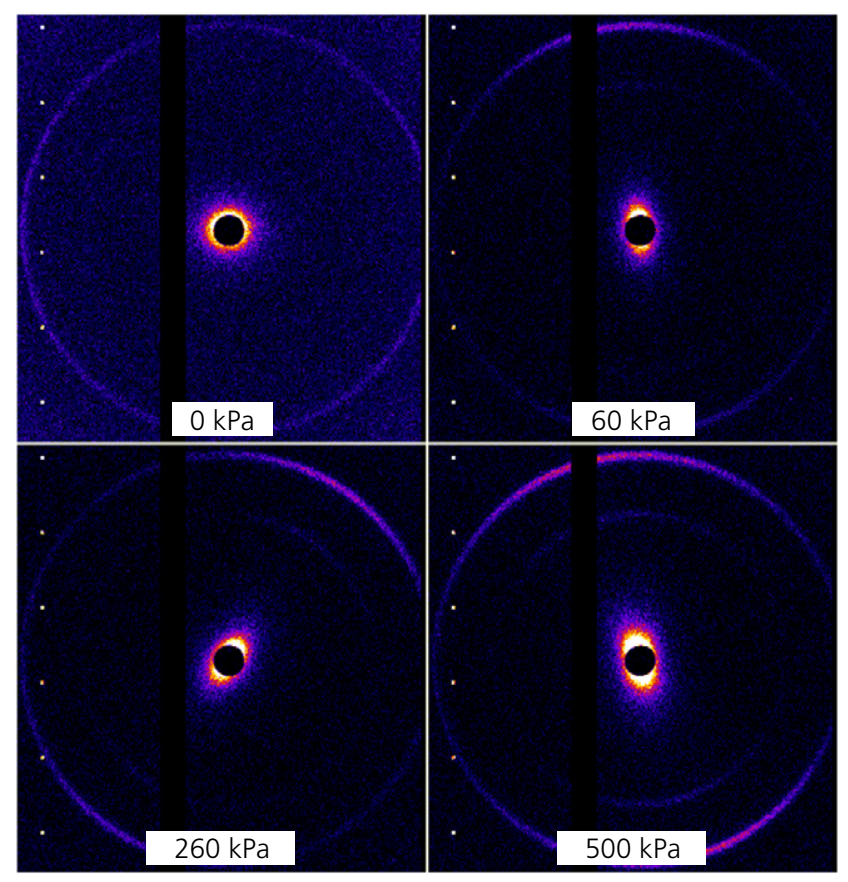

Fig. 4. 2D scattering observations for kaolin slurry consolidated to different stress levels at $\mathrm{pH} 7$

(material density). An isotropic material with randomly oriented clay particles produces a ring at a distance from the centre of the beam on the detector corresponding to the length of the scale producing it. In contrast, an anisotropic structure will cluster the scatterers in a certain direction - for example, horizontally oriented clay platelets will produce a scattering on the vertical axis. In the second data presentation method, the 2D information collapsed into a $1 \mathrm{D}$ plot by averaging the intensity as a function of $\boldsymbol{q}$ over the azimuth or plotting the intensity as a function of the azimuth for a single (or average) $\boldsymbol{q}$.

\section{Effect of $\mathrm{pH}$}

The 2D X-ray scattering results for the suspensions with different $\mathrm{pH}$ values are shown in Fig. 3. All intensities are isotropically distributed in rings with a slight preference for horizontal orientation when the $\mathrm{pH}$ in the suspension increases towards $\mathrm{pH}$ 9. Furthermore, the scattering intensities at small $\boldsymbol{q}$-values increase with increasing $\mathrm{pH}$ - that is, the number of scatterers (thereby the concentration) is higher with increasing $\mathrm{pH}$. This corroborates the expected EF structures that lead to a more open micro-structure with a lower number of scatterers per volume, in suspensions with a $\mathrm{pH}$ below the IEP. 


\section{Effect of stress level}

A systematic study of the effect of consolidation on the emerging X-ray scattering patterns is presented in Fig. 4. Four plots are shown: one for the slurry at $0 \mathrm{kPa}$ and three additional measurements of the independent samples extracted after consolidation at, respectively, $\sigma_{\mathrm{v}}^{\prime}=60,260$ and $500 \mathrm{kPa}$. Similar to the suspensions, the slurry shows an isotropic scattering pattern with low intensity. The structure evolves from isotropic to anisotropic after completion of the first loading step. The inconsequential differences in the orientation between the loading steps stem from the different samples. Finally, the smaller void ratio from consolidation is also seen in the larger number of scatterers, especially at low $\boldsymbol{q}$-values near the centre of the image.

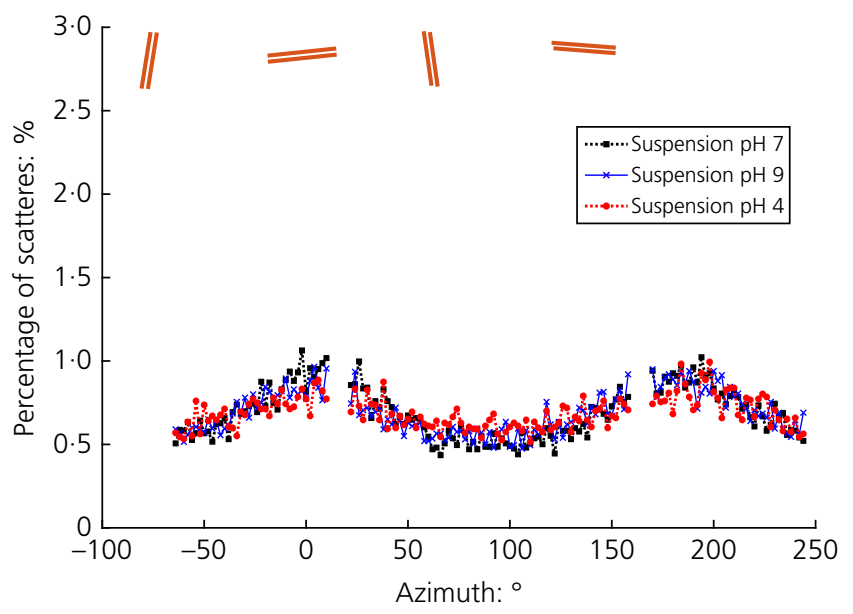

Fig. 5. Distribution of the scattering orientation through the azimuth for suspensions with $\mathrm{pH}=7,9$ and 4
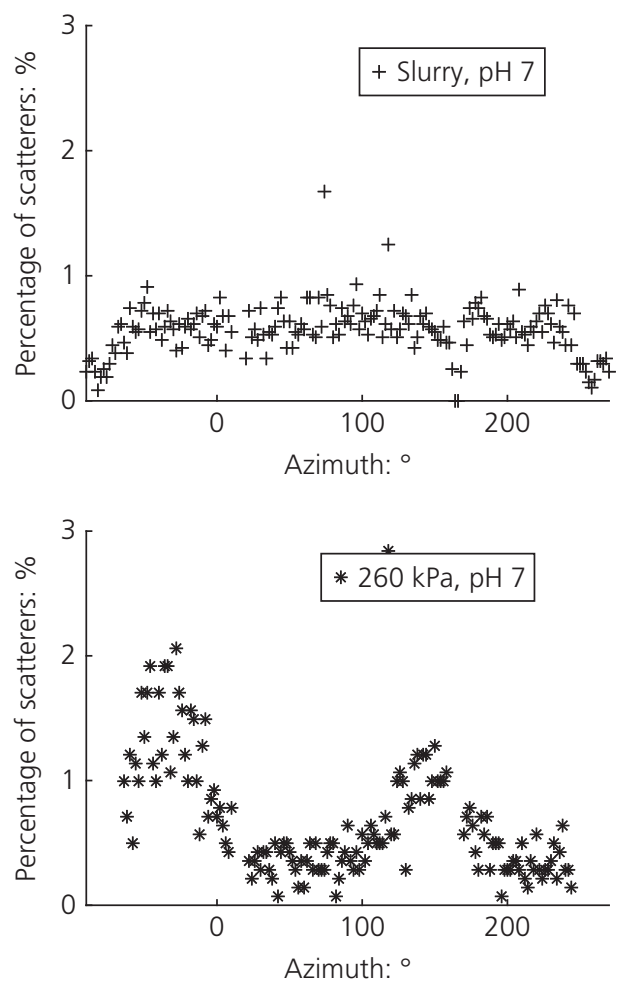

Summary of results

Figures 5 and 6 show the normalised scattering intensities as functions of azimuth at $\boldsymbol{q}=7 \AA$ for, respectively, the suspensions and the loading tests. The orientation of the mineral is shown at the top of the figure.

The results indicate that the $\mathrm{pH}$ of the suspensions does not have much of an effect on the orientation of the kaolinite mineral. All minerals are dispersed with a slight preference for the horizontal orientation. This is corroborated for the slurry at $\mathrm{pH}=7$. A loading history, however, forces an anisotropic structure where the minerals are primarily horizontally aligned, which is already observed at a relatively low consolidation stress of $\sigma_{\mathrm{v}}^{\prime}=60 \mathrm{kPa}$, and logically does not change for higher stress levels.

Finally, Figs 7 and 8 show the absolute scattering intensities as functions of the scattering vector $\boldsymbol{q}$ for both the suspensions and the consolidated samples. The suspensions demonstrate remarkable data consistency, where only the suspension at $\mathrm{pH}=4$ has a slightly lower concentration for larger length scales $\boldsymbol{q}<0.4 \mathrm{~A}^{-1}$, which is expected from the lower concentration associated with EF orientations. The kaolinite $\left(\boldsymbol{q}=0.898 \AA^{-1}\right)$ and illite $\left(\boldsymbol{q}=0.628 \AA^{-1}\right)$ peaks are clearly visible. For the scattering data on the consolidated samples (Fig. 8) new peaks appear between the kaolinite peak and the smallest spacings, which are most probably related to attractive particle interactions that become stronger at smaller void ratios. The increase in intensity as a function of the increased stress level is a more general trend observed in Fig. 8 across the $\boldsymbol{q}$-value range measured.

\section{CONCLUSIONS}

$\mathrm{X}$-ray scattering can be used for monitoring subtle changes on the nano-scale in fine-grained materials in their natural wet state. The WAXS measurements of particle orientation in the suspensions are not affected by the $\mathrm{pH}$ of the electrolyte; this finding is in contrast to prior conceptual
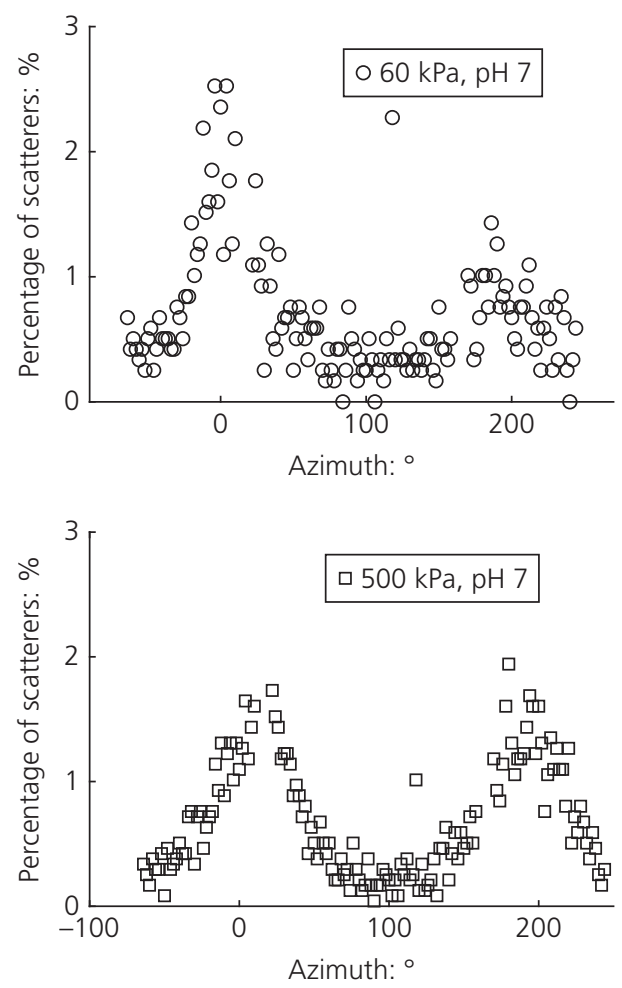

Fig. 6. Distribution of the scattering orientation through the azimuth for kaolin slurry and the subsequent consolidated samples at vertical effective stress levels of 60,260 and $500 \mathrm{kPa}$ 


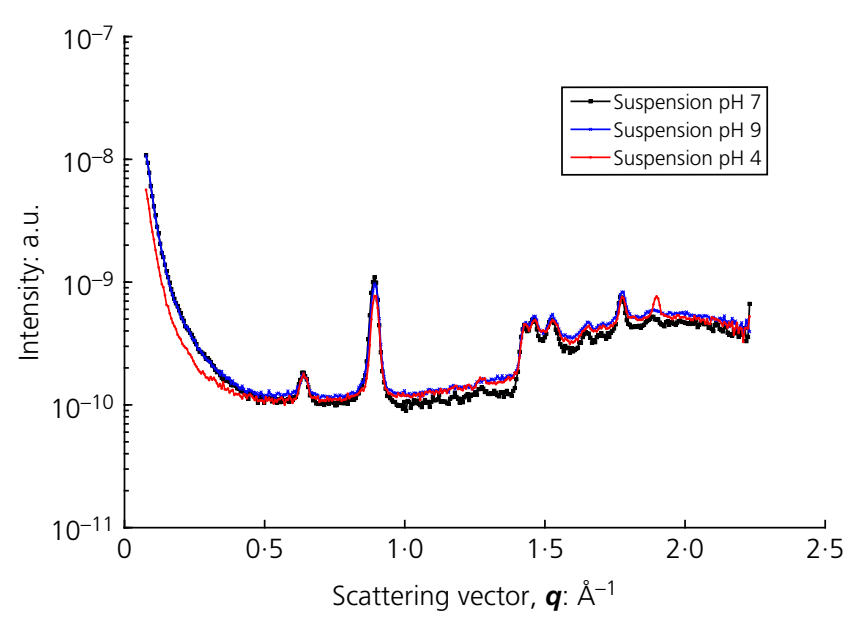

Fig. 7. $1 \mathrm{D}$ curves for the scattering vector $\boldsymbol{q}$ of kaolin suspensions in solutions of $\mathrm{pH}=7,9$ and 4

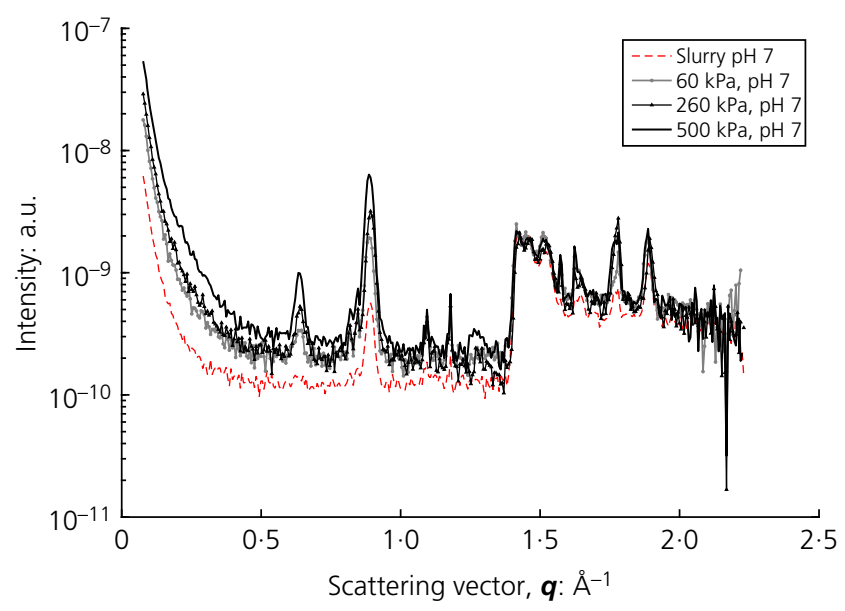

Fig. 8. 1D curves for the scattering vector $\boldsymbol{q}$ for the kaolin slurry and the subsequent consolidated samples at vertical effective stress levels of 60,260 and $500 \mathrm{kPa}$

models that suggest face-to-edge assemblies. The results show that the nano-scale orientations of the clay minerals observed in kaolin suspensions and slurries evolve into an anisotropic system with mainly horizontally aligned particles after 1D oedometric consolidation at already low magnitudes of effective stress $(60 \mathrm{kPa})$. Finally, the bulk density changes can be tracked; however, strains are predominantly on a scale beyond what is accessible for a laboratory WAXS/SAXS instrument.

\section{ACKNOWLEDGEMENTS}

Financial support from the Swedish Research Council (Vetenskapsrådet) under grant 491401 and FORMAS under grant 2016-01070 is gratefully acknowledged.

\section{REFERENCES}

Ben Rhaïem, H., Pons, C. H. \& Tessier, D. (1987). Factors affecting the microstructure of smectites: role of cation and history of applied stresses. Proceedings of international clay conference, Denver, 1985 (eds L. G. Schultz, H. van Olphen and F. A. Mumpton), pp. 292-297. Bloomington, IN, USA: The Clay Minerals Society.

Birmpilis, G., Dijkstra, J. \& Hall, S. A. (2017). Miniature sampling method in experimental geomechanics for soft soils. Proceedings of the 17th international conference on experimental mechanics
(ICEM 17), Rhodes, Greece (eds P. Giovine, P. M. Mariano and G. Mortara). pp. 49-58. Cham, Switzerland: Birkhäuser.

Bohor, B. F. \& Hughes, R. E. (1971). Scanning electron microscopy of clay and clay minerals. Clays Clay Miner. 19, 49-54.

Brindley, G. W. \& Kurtossy, S. S. (1962). Quantitative determination of kaolinite by X-ray diffraction. Am. Mineral. 46, No. 11-12, 1205-1215.

Deirieh, A. (2016). From clay slurries to mudrocks: a cryo-SEM investigation of the development of the porosity and microstructure. $\mathrm{PhD}$ dissertation, Massachusetts Institute of Technology, Cambridge, MA, USA.

Deirieh, A., Chang, I. Y., Whittaker, M. L., Weigand, S., Keane, D., Rix, J., Germaine, J. T., Joester, D. \& Flemings, P. B. (2018). Particle arrangements in clay slurries: the case against the honeycomb structure. Appl. Clay Sci. 152, 166-172.

Delage, P. (2010). A microstructure approach to the sensitivity and compressibility of some Eastern Canada sensitive clays. Géotechnique 60, No. 5, 353-368, https://doi.org/10.1680/geot. 2010.60.5.353.

Delage, P. \& Lefebvre, G. (1984). Study of the structure of a sensitive Champlain clay and of its evolution during consolidation. Can. Geotech. J. 21, No. 1, 21-35.

Diamond, S. (1970). Microstructure and pore structure of impact compacted clays. Clays Clay Miner. 19, No. 4, 239-249.

Gillot, J. E. (1970). Fabric of Leda clay investigated by optical, electron-optical, and X-ray diffraction methods. Engng Geol. 4, No. 2, 133-153.

Glatter, O. \& Kratky, O. (1982). Small angle X-ray scattering. London, UK: Academic Press.

Grim, R. E. (1953). Clay mineralogy. New York, NY, USA: McGraw- Hill.

Hanley, H. J. M., Straty, G. C. \& Tsvetkov, F. (1994). A small angle neutron scattering study of a clay suspension under shear. Langmuir 10, No. 9, 3362-3364.

Hattab, M. \& Fleureau, J. M. (2010). Experimental study of kaolin particle orientation mechanism. Géotechnique 60, No. 5, 323-331, https://doi.org/10.1680/geot.2010.60.5.323.

Hattab, M., Hammad, T., Fleureau, J. M. \& Hicher, P. Y. (2013). Behaviour of a sensitive marine sediment: microstructural investigation. Géotechnique 63, No. 1, 71-84, https://doi.org/ 10.1680/geot.10.P.104.

Houghton, H. A. \& Donald, A. M. (2008). An environmental scanning electron microscopy study of aqueous gibbsite suspensions. Scanning 30, No. 3, 223-227.

Iñigo, A. C., Tessier, D. \& Pernes, M. (2000). Use of X-ray transmission diffractometry for the study of clay-particle orientation at different water contents. Clays Clay Miner. 48, No. 6, 682-692.

Jung, Y., Son, Y. H., Lee, J. K., Phuoc, T. X., Soong, Y. \& Chyu, M. K. (2011). Rheological behavior of clay-nanoparticle hybrid-added bentonite suspensions: specific role of hybrid additives on the gelation of clay-based fluids. ACS Appl. Mater. Interfaces 3, No. 9, 3515-3522.

Lee, S., Fischer, T. B., Stokes, M. R., Klingler, R. J., Ilavsky, J., McCarty, D. K., Wigand, M. O., Derkowski, A. \& Winans, R. E. (2014). Dehydration effect on the pore size, porosity, and fractal parameters of shale rocks: ultrasmallangle X-ray scattering study. Energy Fuels 28, No. 11, 6772-6779.

Leu, L., Georgiadis, A., Blunt, M. J., Busch, A., Bertier, P., Schweinar, K., Liebi, M., Menzel, A. \& Ott, H. (2016). Multiscale description of shale pore systems by scanning SAXS and WAXS microscopy. Energy Fuels 30, No. 12, 10282-10297.

Martin, R. T. \& Ladd, C. C. (1975). Fabric of consolidated kaolinite. Clays Clay Miner. 23, 17-25.

Mitchell, J. K. \& Soga, K. (2005). Fundamentals of soils behavior, 3rd edn. John Wiley \& Sons, Hoboken, NJ, USA.

Morvan, M., Espinat, D., Lambard, J. \& Zemb, T. h. (1994). Ultrasmall- and small-angle X-ray scattering of smectite clay suspensions. Colloids Surf., A 82, No. 2, 193-203.

Pedrotti, M. \& Tarantino, A. (2017). An experimental investigation into the micromechanics of non-active clays. Géotechnique $\mathbf{6 8}$, No. 8, 666-683, https://doi.org/10.1680/jgeot.16.P.245.

Pignon, F., Magnin, A., Piau, J. M., Cabane, B., Lindner, P. \& Diat, O. (1997). Yield stress thixotropic clay suspension: investigations of structure by light, neutron, and X-ray scattering. Phys. Rev. E 56, No. 3, 3281-3289. 
Pujari, A., Dougherty, L., Mobuchon, C., Carreau, P. J., Heuzey, M. C. \& Burghardt, W. R. (2011). X-ray scattering measurements of particle orientation in a sheared polymer/clay dispersion. Rheol. Acta 50, No. 1, 3-16.

Pusch, R. (1970). Microstructural change in soft quick clay at failure. Can. Geotech. J. 7, No. 1, 1-7.

Quigley, R. M. \& Thompson, C. D. (1966). The fabric of anisotropically consolidated sensitive marine clay. Can. Geotech. J. 3, No. 2, 61-73.

Santamarina, J. C. (2003). Soil behavior at the microscale: particle forces. In Soil behavior and soft ground construction (eds J. T. Germaine, T. C. Sheahan and R. Whitman), pp. 25-56. Reston, VA, USA: The Geo Institute of the American Society of Civil Engineers.
Tarantino, A. \& De Col, E. (2008). Compaction behaviour of clay. Géotechnique 58, No. 3, 199-213, https://doi.org/10.1680/geot. 2008.58.3.199.

Van Olphen, H. (1977). Clay colloid chemistry: for clay technologists, geologists and soil scientists. New York, NY, USA: John Wiley.

Villar, M. V., Gómez-Espina, R. \& Gutiérrez-Nebot, L. (2012). Basal spacings of smectite in compacted bentonite. Appl. Clay Sci. 65, 95-105.

Wang, Y. H. \& Siu, W. K. (2006). Structure characteristics and mechanical properties of kaolinite soils. I. Surface charges and structural characterizations. Can. Geotech. J. 43, No. 6, 587-600.

Zhang, L., Jahns, C., Hsiao, B. S. \& Chu, B. (2003). Synchrotron SAXS/WAXD and rheological studies of clay suspensions in silicone fluid. J. Colloid Interface Sci. 266, No. 2, 339-345.

\section{HOW CAN YOU CONTRIBUTE?}

To discuss this paper, please submit up to 500 words to the editor at journals@ice.org.uk. Your contribution will be forwarded to the author(s) for a reply and, if considered appropriate by the editorial board, it will be published as a discussion in a future issue of the journal. 